\title{
Documento
}

\section{Plano Nacional de Pós-Graduação: subsídios apresentados pela ANPEd}

\section{Introdução}

AAssociação Nacional de Pós-Graduação e Pesquisa em Educação (ANPEd) ${ }^{1}$ tem se voltado para o desenvolvimento e a consolidação do ensino de pósgraduação e da pesquisa na área de educação no Brasil. Em sua condição de representante da área de pósgraduação em educação, lhe foram solicitadas, pela fundação Coordenação de Aperfeiçoamento de Pessoal de Nível Superior (CAPES), sugestões com vista à elaboração do V Plano Nacional de Pós-Graduação (PNPG). Considerando a exigüidade do prazo estabelecido pela CAPES para o encaminhamento dos

\footnotetext{
1 Associação civil, sem fins lucrativos, fundada em 1978.
} Constitui-se de sócios institucionais (Programas de Pós-Graduação em Educação, atualmente em número de 66) e de sócios individuais (professores, pesquisadores, mestrandos e doutorandos, atualmente cerca de 1.200). Abriga, em sua estrutura, vinte e um grupos de trabalho e dois grupos de estudo, estrutura que lhe dá sustentação e suporte acadêmico e científico. subsídios, a ANPEd optou tão-somente por reafirmar alguns dos pressupostos que, a seu ver, são indispensáveis a uma política de pós-graduação em educação no país.

A ANPEd compreende que a educação, de modo geral e especificamente o ensino superior e os estudos pós-graduados, deve ser objeto de atenção privilegiada do governo, da comunidade científica e da sociedade como um todo. Por certo, não é exclusividade da área de educação reconhecer a importância de políticas eficientes e duradouras, capazes de impulsionar o desenvolvimento científico e tecnológico do país. Nessas circunstâncias, a ANPEd partilha do consenso de que o debate no campo da educação pósgraduada não se contém nos limites restritos de prazos estabelecidos, mas, ao contrário, se obriga ao diálogo amplo e permanente com as comunidades científica e política do país. Só assim serão contempladas as relações da CAPES com as demais instâncias da sociedade. É precisamente nesse sentido que a ANPEd reafirma seu interesse em assegurar sua participação e intervenção em todas as fases de discussão e de elaboração do PNPG. 


\section{Pressupostos, no âmbito da área de educação}

A ANPEd entende que são de natureza vária e diversa os pressupostos das questões pertinentes ao campo da pós-graduação em educação, de presença indispensável em uma política nacional de pós-graduação.

1. Considera que a definição dos rumos do sistema de estudos pós-graduados supõe sua estreita vinculação com a reforma da educação superior do país, em franco processo de elaboração, da qual, por sua vez, se espera íntima articulação com o sistema nacional de educação, do qual a educação superior é parte constitutiva.

2. Nesse contexto, compreende que a elaboração e implementação de um PNPG sejam fruto de uma política de Estado para o ensino e a pesquisa no país, com vista a evitar a ocorrência de decisões vulneráveis ao jogo das circunstâncias. O PNPG, junto com o Plano Nacional de Educação (PNE), deve exercer um papel decisivo nos rumos da pós-graduação, integrando-a ao sistema universitário nacional e às políticas de desenvolvimento socioeconômico e científico-tecnológico do país.

A pós-graduação não se coloca absolutamente à parte no sistema educacional. Pelas novas Diretrizes e Bases da Educação Nacional (Lei no 9.294/96), integra-se na educação superior e articula-se com os demais níveis, sendo seu papel delineado nas inter-relações e exigências propostas pela atual legislação da educação brasileira, mas, acima de tudo, pelo movimento histórico-social em que se insere.

(ANPEd, A avaliação da pós-graduação em debate. São Paulo, set. 1999, p. 35)

3. Afirma a institucionalização da pesquisa em educação como essencialmente humanitária e social. Seu objeto central de estudo é o fenômeno educativo, nas mais distintas formas e dimensões em que socialmente se manifesta. Os estudos pós-graduados em educação formam especialmente docentes e pesquisadores para as instituições de ensino superior do país. São eles, os docentes/pesquisadores com formação específica na área, que sustentam a produção científica, promovem e fazem avançar este campo de conhecimento. Tal é a natureza do perfil epistemológico da área. Como se sabe, possuir especificidade e perfil epistemológico próprios é requisito indispensável à constituição de uma área de conhecimento científico, entendimento este presente nas instituições que tratam de ciência e de tecnologia - em seu planejamento, avaliação e fomento -, como é o caso da CAPES.

4. Se é especificidade da área de educação a formação científica de mestres e doutores, seu impacto social supõe, necessariamente, múltiplas mediações sociopolíticas. Nessa perspectiva, o modelo privilegiado da pós-graduação em educação é o acadêmico. Em particular,

\footnotetext{
[...] não há como nem por que diminuir o peso e o lugar ocupado pelo mestrado. $\mathrm{O}$ mestrado continua tendo papel fundamental de preparo de profissionais-pesquisadores para a área de educação. Para a grande maioria do corpo discente dos nossos programas, a passagem pelo mestrado é condição sine qua non para enfrentar a carga acadêmica e científica que representa a elaboração de uma tese de doutorado, além do que o mestrado não tem representado necessariamente etapa preliminar de estudos que culminem no doutorado; e isto não nos parece nada problemático. (CAPES, Documento da área de educação; período de referência 1996/1997/1998)
}

É nesse projeto de formação que a área enraíza suas bases, e é assim que tal formação deve ser compreendida, como "processo de educação", pressuposto considerado estratégico para alcançar e manter um nível elevado de produção de conhecimento, cujo critério de excelência abrange prioritariamente o valor científico da produção, mas também seu impacto e contribuição no contexto social. Na mesma perspectiva, um ponto a ser revisto é o tempo médio de titulação do mestrado e do doutorado, com base no que as diferentes áreas vêm apontando como tempo 
ideal para a formação de mestres e doutores, formação essa a ser sustentada por uma política de bolsas mais abrangente.

5. O impacto social das inúmeras atividades advindas do amplo "raio de ação" no qual tanto os programas como os docentes-pesquisadores em educação atuam e contribuem merece registro particular. A ANPEd destaca a importância de que se qualifique o impacto da pós-graduação em educação na criação de novos grupos de pesquisa, não apenas na elaboração e implementação de convênios com instituições nacionais e internacionais, na criação e consolidação de novos cursos de mestrado e doutorado, mas também na formação de quadros para a gestão de instituições educacionais e movimentos sociais, sua vinculação com as redes de ensino fundamental e médio, além de outras significativas atuações na extensão universitária. A maneira de atuar da pós-graduação em educação - inserindo-se fortemente na dinâmica acadêmico-social, gerando atividades solidárias, trabalhando cooperativamente em equipes e com missões sociais de amplo alcance nos sistemas de ensino como um todo - constitui-se em uma dinâmica também específica da área e de sua produção. Esta dinâmica, respeitando as exigências e a singularidade do âmbito estritamente acadêmico, enriquece e potencializa a pósgraduação, fazendo-a responder aos desafios de outras instâncias e níveis educacionais.

6. Por sua vez, a ANPEd apóia a recomendação apresentada no relatório do Grupo de Trabalho da Área de Ciências Humanas, Letras, Lingüística e Artes quanto ao necessário investimento - ou indução - de áreas temáticas para atender às novas demandas da sociedade. Dentre elas destacam-se: avaliação institucional e de sistemas, educação ambiental, educação especial, educação a distância, informática e educação, e métodos quantitativos em educação (Infocapes, v. 9, p. 44).

7. É nesse contexto que se deve compreender o fomento como política de sustentação aos progra- mas já consolidados, e de apoio e incentivo aos que iniciam o percurso. A este respeito, a ANPEd chama a atenção para os seguintes aspectos:

7.1 A valorização do mérito científico como critério para o fomento é reconhecido pela área como altamente significativa. No entanto, este não pode ser considerado critério excludente ou gerador de exclusão em relação aos programas mais recentes e localizados em regiões menos desenvolvidas do país. As numerosas análises produzidas e publicadas pela CAPES (Infocapes; anais de reuniões e seminários) sobre a situação da pósgraduação nacional constatam, desde muito, um visível desequilíbrio no que se refere ao fomento de diferentes programas, nas diferentes regiões. Isto caracteriza um quadro que contraria o critério de democratização do fomento, princípio defendido pela ANPEd para a área. Assim, se a política de valorização da excelência é estratégia para o apoio à criação e consolidação de centros de competência e excelência, deve também apoiar o desenvolvimento de programas de pesquisa e pós-graduação recém-criados e distantes das chamadas "ilhas de excelência", para que possam vir a ocupar esses espaços com crescente e equivalente qualidade acadêmica.

7.2 Só a democratização do fomento possibilitará condições acadêmicas e de infra-estrutura para o alcance da democratização da qualidade da pósgraduação e da pesquisa. Nenhum PNPG terá viabilidade se não forem revertidos o reconhecido déficit de docentes e pesquisadores e a degradação da infra-estrutura da pesquisa das instituições de ensino superior públicas no país. Para tanto, são necessários investimentos efetivos, abrangendo equipamentos, instalações, redes e terminais de informática, bibliotecas, dentre outros, além da contratação de serviços para instalação, manutenção, operação, modificação e adaptação dessa infra-estrutura. De acordo com o Infocapes (v. 9, p. 16), é necessário 
[...] reformular a matriz orçamentária das universidades, com base na qualidade e dimensão de seus projetos de pesquisa e pós-graduação, de modo a dotá-las de recursos institucionais que possibilitem o custeio da infra-estrutura necessária para os mesmos.

\section{3 $\mathrm{O}$ anteriormente exposto nos leva a conside-} rar a relação entre a área da educação e as demais. Neste sentido, a natureza dos estudos, da aplicação e dos resultados dessas diferentes áreas evocam diferentes necessidades e critérios que precisam ser considerados nos processos de implementação e de avaliação dos programas a elas vinculados. É nessa direção que José Luiz Fiorin, ex-representante da área de Letras e Lingüística (no texto intitulado Considerações em torno do novo processo de avaliação, publicado em Infocapes, v. $\left.6, \mathrm{n}^{\circ} 2,1998\right)$, se pronuncia:

A questão é se é possível e desejável a avaliação de todas as áreas pelos mesmos critérios. A resposta é não e a razão é que elas são diferentes. Se são diversas, não é desejável desconhecer essa dissimilitude. Antes, porém, de começar a desenvolver essa questão, gostaria de repudiar energicamente duas posições muito freqüentes. A primeira é o discurso da diferença, que serve para ocultar deficiências: todas as áreas podem ser avaliadas por parâmetros de qualidade, não se pode pedir condescendência na avaliação de determinados ramos do conhecimento, por se considerá-los mais frágeis; a segunda é aquela que diz que nem todas as áreas têm o mesmo nível de desenvolvimento e que, portanto, umas são melhores que as outras.

As áreas são diferentes, porque é diversa a natureza dos conhecimentos que o homem construiu ao longo da história. Há áreas em que o conhecimento é universal em sentido estrito, já que não operam com fenômenos históricos, não dizem respeito a determinadas formações sociais, a certo período histórico, a uma língua ou uma literatura específicas. Há outras áreas que trabalham com algo que é mais particular, mais contingente. Não se está dizendo que o conhecimento dessas áreas não constitua fortes arcabouços teóricos. O estilo desses ramos do co- nhecimento não é a interpretação descompromissada, leve, livre e solta. Eles, como qualquer ciência, têm preocupação com a generalização e com a verificação dos resultados (afinal, já diziam os medievais: Nominantur singularia, sed significantur universalia). O que se está mostrando é que, nesses domínios, o conceito de universal não tem um valor forte. Há áreas em que a obsolescência do conhecimento é um fato, enquanto há outras em que não existe esse envelhecimento.

8. O modelo da avaliação é reconhecidamente homogeneizador e tende a uma padronização dos programas de pós-graduação, caminhando, portanto, na direção oposta das discussões e análises que buscam contemplar sua rica diversidade. Nas várias áreas, são diferentes a natureza da formação de doutores, as modalidades de produção de conhecimento, as formas de publicação da produção intelectual, os mecanismos de intercâmbio e cooperação acadêmicos. Várias alternativas ajudariam a flexibilizar a sistemática de avaliação, enfatizando seu caráter diagnóstico, com vista a respeitar as especificidades das áreas e programas: contemplar a história do programa numa escala temporal (de no mínimo quatro anos); levar em conta seu impacto local, regional, nacional e internacional, via atuação dos egressos e produção científica do conjunto daqueles que o compõem; incorporar efetivamente os dados de auto-avaliação que por sua vez devem ser reconhecidos no âmbito da CAPES (ANPEd, A avaliação da pós-graduação em debate. São Paulo: ANPEd, set. 1998, p. 52).

9. A flexibilidade também pode ocorrer no momento de elaboração dos pareceres finais da avaliação: cursos consolidados devem ser analisados num bloco e cursos novos em outro; programas só com mestrado num bloco, programas com mestrado e doutorado em outro. Este olhar aos subconjuntos, sem perder a visão do todo, permitiria relativizar eventuais discrepâncias nas análises individuais dos programas e corrigir possíveis distorções (idem, p. 53) que acabam prejudicando, excluindo cursos e programas. Urge, portanto, reverter a lógica classificatória e ins- 
tituir uma lógica que contemple principalmente: o diagnóstico, acompanhamento e incremento dos programas, segundo a sua relevância regional e as condições em que atuam; os mecanismos de auto-avaliação e não apenas avaliação externa; a relativização do tempo médio de titulação, dentre outros. A este respeito, a área de educação tem produção significativa que pode ser disponibilizada para o refinamento e a adequação do modelo de avaliação.

10. Vale registrar, também, que a manutenção ou mesmo a diminuição do montante de recursos disponibilizados para financiar a pós-graduação tem contribuído para uma grave distorção do conceito de avaliação entendida como processo: ao instrumentalizar as decisões sobre o fomento, a avaliação acaba tornando-se mecanismo balizador e justificador de ex- clusão. A reversão desse quadro implica decisões no sentido de garantir que o montante de recursos esteja atrelado a necessidades sociais cada vez mais amplas e a retornos/compensações aos programas que, qualificadamente, responderem às demandas já colocadas e estiverem abertos a inserir no espectro da sua atuação outras que venham a ser identificadas. Acrescenta-se que, além de garantir recursos na mesma proporção da ampliação das demandas identificadas e atendidas, seria importante uma política conjunta dos órgãos de fomento. E desejável também que se encontrem formas de pressionar a constituição e o funcionamento das fundações estaduais de pesquisa, a fim de que venham a cumprir suas funções.

Rio de Janeiro, julho de 2004 